\title{
What can fertility indicators tell us about pronatalist policy options?
}

\author{
John Bongaarts*
}

\begin{abstract}
The identification and implementation of ways to avert the adverse future consequences of rapid population ageing represent urgent new public policy challenges. This paper synthesises the available knowledge on pronatalist policy options and assesses their potential impact by examining three fertility indicators: the total fertility rate, the tempo-adjusted total fertility rate and the personal ideal family size. Using recent data from thirteen European countries, the TFR is found to be lower than the ideal family size in each population. The two main reasons for this gap are tempo effects and economic, social and biological obstacles to the implementation of reproductive preferences. These factors together are estimated to average approximately 0.8 to 0.9 births per woman. Policy options to raise fertility without interfering with existing reproductive preferences are proposed. The concluding section briefly examines the impact of an increase in fertility on future trends in the old-age dependency ratio.
\end{abstract}

\section{Introduction}

Europe faces an unprecedented demographic future. Very low fertility and rising life expectancy are leading to a shrinking labour force and a rapidly ageing population. These trends have a range of adverse social and economic effects which include reduced growth in standards of living and a rise in pension and health care costs (OECD 1998, 2001, 2006; United Nations 2007a; World Bank 1994). Expenditures by widely implemented pay-as-you-go public pensions, which rely on transfers from younger to older generations, are becoming increasingly burdensome on the contributors as old-age 'dependency rates' rise to record levels. The European Commission's White Paper The demographic future of Europe-from challenge to opportunity (2006) concluded that “... public finances risk becoming unsustainable in many countries, thereby compromising the future equilibrium of pension and social security systems in general. Allowing

* John Bongaarts, Population Council, One Dag Hammarskjold Plaza, New York, NY 10017, USA. Email: JBongaarts@popcouncil.org 
public spending linked to ageing to create budget deficits would lead to an intolerable spiral of debt" (p.7). A study by the International Monetary Fund suggests that failure to address these fiscal stresses in pension systems "could inflict serious macroeconomic and structural damage, both on the domestic economy and, in the case of large industrial countries through international linkages, on the world economy" (Chand and Jaeger 1996, p.1).

Under these changing demographic conditions, identifying and implementing ways to reform public support systems for the elderly have become urgent new challenges for public policy. A range of options is under consideration: reduced benefits, increased taxes, higher labour force participation, delayed retirement, privatisation of pension systems, etc. Until recently, demographic options, and in particular pronatalist measures, have been largely absent from this debate. Of course, most governments in the developed world already have policies that provide families with certain benefits, but these are in general not explicitly pronatalist. Governments have avoided pronatalist policies for several reasons: a reluctance to interfere in the family decision making on such a private matter, a lack of urgency, a hope that low fertility will reverse itself, the potential high cost of intervention, and uncertainty about its effectiveness. In addition, it is awkward to implement pronatalist measures at home while supporting programmes to reduce fertility in developing countries. Possible measures to raise fertility include fiscal benefits for families with children, as well as measures to assist working parents with free or subsidised daycare, flexible hours, leave options, etc. An important but still unresolved question is whether pronatalist policies can have a significant fertility impact. Assessments of past efforts differ: Demeny (2003) finds their effects "at best limited" (p.760), and Van de Kaa (2006) concludes that "[f]ertility is largely beyond government control" (p.204). But Calot (2006) argues that family policies can raise fertility substantially in the short run and by "a few tenths of a child per woman" (p.154) in the long run, which would be sufficient to "obtain simple replacement fertility in Western Europe" (p.154). Other analysts have positions that fall between these extremes (e.g. Caldwell et al. 2002; Gauthier 2007; McDonald 2006).

This paper presents a synthesis of available knowledge on general pronatalist policy options and assesses the potential impact of such policies using widely available fertility indicators. The analysis will be confined to data from Europe. The first section describes the three main indicators used in the analysis and their strength and weaknesses. This is followed by a discussion of policy options to raise fertility without interfering with existing reproductive preferences. A concluding section briefly examines the impact of an increase in fertility on population ageing. 


\section{Fertility Indicators}

A range of fertility indicators are available to monitor fertility trends and to analyse their determinants. Some are simple to calculate and readily available (e.g. crude birth rate and total fertility rate) while others are complex and highly demanding of detailed data which are not available for many countries (e.g. life table based measures requiring data on births by age, parity and/or duration since last birth). Policy makers prefer simple indicators that are easy to interpret and the choice of indicators for policy assessment should reflect these interests. The present study will rely on the following three indicators of fertility preferences and behaviour:

-Total Fertility Rate (TFR) equals the average life-time number of births per woman implied by current age-specific birth rates. It is the most widely used and available indicator of fertility quantum observed in a time period (typically a year). This measure appears to be easy to interpret because it is expressed in births per woman, but there is an inherent complexity of this indicator that is hidden for many users. The TFR is a hypothetical measure for a synthetic cohort, which is readily misinterpreted by the public and non-demographers. For example, media accounts often interpret the TFR as the "the number of births women are having". As discussed below, this cohort interpretation is not an accurate one since the TFR often provides a distorted view of the underlying behaviour of cohorts when the timing of births changes.

-Tempo-adjusted total fertility rate (ATFR) is a variant of the TFR designed to remove the distorting effect on the TFR of changes in the timing of childbearing. It is a pure period quantum measure estimating the TFR that would have been observed in the absence of timing changes. The difference between the TFR and the ATFR is called a tempo effect or distortion. The ATFR also equals the (constant) TFR that would be observed in the future if fertility conditions and the shape of the fertility schedule by age were to remain fixed. To calculate the $A T F R$, the procedure proposed by Bongaarts and Feeney $(1998,2006)$ will be used here because it is relatively undemanding of data and can therefore be applied to many countries. An alternative, more complex method has been developed by Kohler and Ortega (2002), but it is not clear which method is more accurate (Sobotka 2003). Sobotka (2008) uses the Bongaarts-Feeney method and states, "[g]iven the limited data availability for computing more sophisticated indicators, I consider this indicator a reasonably good approximation of fertility quantum, especially when summarised for longer time periods". The present study relies on five-year averages of the TFR and ATFR calculated by Sobotka (2004). 
-Ideal family size (IFS) is the most widely used preference indicator ${ }^{1}$. Estimates of $I F S$ derived from surveys are sensitive to the wording of the relevant questions posed in the survey. In particular, some questions measure the respondent's view of what a desired family size would be for society while other questions aim to elicit the family size desired by the individual. To avoid confusion, the 2001 round of the Eurobarometer survey asked two questions on family size ideals: "Generally speaking, what do you think is the ideal number of children for a family?" and "... for you personally, what would be the ideal number of children for a family?" (Goldstein et al. 2003). The analysis presented below draws on estimates of IFS obtained from women aged 20-34 using this last question.

It should be noted that none of these indicators measure the actual childbearing of women over their lifetimes. Indicators of cohort fertility are of course available and the simplest of these is the cohort completed fertility rate which equals the average number of births per woman at the end of the childbearing years. This is an unambiguous measure of the quantum of fertility but it has an important drawback: it does not provide information on fertility behaviour during recent years because the childbearing of cohorts is spread over several decades in the past. Period measures such the TFR and ATFR avoid this problem, if at the cost of introducing a conceptual complexity - in particular the tempo distortion - which does not exist for cohort measures.

Estimates of the TFR and ATFR for 1995-2000 for 26 European countries are presented in Table 1 (Sobotka 2004). The (unweighted) averages of these estimates equal 1.50 and 1.78 birth per woman, respectively. Fertility varies substantially among countries with the TFR ranging from 1.17 in Latvia to 2.06 in Iceland and the ATFR ranging from 1.46 in Spain to 2.34 in Iceland. For a subgroup of 13 countries, estimates of IFS from the Eurobarometer survey are also available (last column of Table 1). In this subgroup, the IFS averaged 2.21 births per woman with a range from 1.7 in Austria and West Germany to 2.5 in England and Wales, Finland, France and Ireland. No attempt will be made here to summarise the extensive literature on the social, economic, institutional, biological and policy causes of variation in fertility and preferences among European countries (see Andersson and Neyer 2004; Caldwell and Schindlmayr 2003; Frejka et al. 2008; Kohler et al. 2006; Morgan and Taylor 2006; McDonald 2000; Sobotka 2008).

Another widely used preference indicator is expected family size, calculated as the number of children the respondent has at the time of the survey plus any additional births wanted in the future. Expected family size is usually lower than ideal family size (Goldstein et al. 2003). This measure is not used in the present analysis because it combines actual and intended childbearing and hence is affected by obstacles to the implementation of preferences. 
Table 1:

Observed and tempo adjusted TFR 1995-2000 for 26 countries and ideal family size in 2001 for 13 countries

\begin{tabular}{|c|c|c|c|c|}
\hline & $\begin{array}{c}\text { Total } \\
\text { fertility } \\
\text { rate }\end{array}$ & $\begin{array}{c}\text { Tempo } \\
\text { adjusted } \\
\text { TFR }\end{array}$ & $\begin{array}{c}\text { Tempo } \\
\text { effect }\end{array}$ & $\begin{array}{c}\text { Ideal } \\
\text { family } \\
\text { size } \\
\end{array}$ \\
\hline Austria & 1.36 & 1.58 & 0.22 & 1.7 \\
\hline Bulgaria & 1.20 & 1.48 & 0.28 & \\
\hline Czech Republic & 1.18 & 1.73 & 0.55 & \\
\hline Denmark & 1.79 & 2.04 & 0.25 & 2.4 \\
\hline England and Wales & 1.71 & 1.85 & 0.14 & 2.5 \\
\hline Estonia & 1.28 & 1.77 & 0.49 & \\
\hline Finland & 1.75 & 1.89 & 0.14 & 2.5 \\
\hline France & 1.79 & 1.96 & 0.17 & 2.5 \\
\hline Greece & 1.30 & 1.63 & 0.33 & 2.3 \\
\hline Hungary & 1.44 & 1.76 & 0.32 & \\
\hline Iceland & 2.06 & 2.34 & 0.28 & \\
\hline Ireland & 1.89 & 2.18 & 0.29 & 2.5 \\
\hline Italy & 1.21 & 1.64 & 0.43 & 2.1 \\
\hline Latvia & 1.17 & 1.55 & 0.38 & \\
\hline Lithuania & 1.40 & 1.65 & 0.25 & \\
\hline Macedonia & 1.91 & 2.13 & 0.22 & \\
\hline Netherlands & 1.60 & 1.73 & 0.13 & 2.1 \\
\hline Norway & 1.85 & 2.07 & 0.22 & \\
\hline Poland & 1.48 & 1.76 & 0.28 & \\
\hline Portugal & 1.47 & 1.73 & 0.26 & 2.0 \\
\hline Romania & 1.31 & 1.52 & 0.21 & \\
\hline Slovakia & 1.40 & 1.74 & 0.34 & \\
\hline Slovenia & 1.26 & 1.68 & 0.42 & \\
\hline Spain & 1.18 & 1.46 & 0.28 & 2.0 \\
\hline Sweden & 1.57 & 1.85 & 0.28 & 2.4 \\
\hline West Germany (former FRG) & 1.38 & 1.51 & 0.13 & 1.7 \\
\hline Average 26 countries & 1.50 & 1.78 & 0.28 & \\
\hline $\begin{array}{l}\text { Average } 13 \text { countries with } \\
\text { ideal family size estimate }\end{array}$ & 1.54 & 1.77 & 0.23 & 2.21 \\
\hline
\end{tabular}

Sources: Sobotka 2004, Goldstein et al. 2003.

All these fertility indicators are subject to measurement error. The TFR is usually quite accurate because vital registration is virtually complete in European countries, but the tempo-adjusted TFR contains a potential error if the assumptions on which the adjustment is based do not hold or if small errors exist in estimates of the mean age at childbearing. In addition, the reported personal ideal family size may be influenced by the views of others and survey-based estimates contain inevitable sampling errors. Figure 1 plots country estimates of these three indicators along the vertical axis and cohort fertility along the 
horizontal axis. Cohort fertility is estimated for women born around 1970 who reached their peak childbearing years in 1995-2000 (Council of Europe 2006) ${ }^{2}$ Two key conclusions emerge from these data. First, and most important, in every country the ideal family size exceeds the tempo-adjusted TFR which in turn exceeds the TFR. As discussed below, this finding has significant policy implications. Second, the IFS exceeds cohort fertility and the TFR falls short of cohort fertility in every country. In contrast, there is no systematic difference between cohort fertility and the adjusted TFR, and these two indicators are highly correlated. This finding confirms that the TFR in all 26 countries contains a downward distortion due to a rising age at child bearing and that the ATFR provides an approximate adjustment for this distortion. Further discussion of this issue can be found in Bongaarts and Feeney $(1998,2006)$.

Figure 1:

Total fertility, tempo adjusted total fertility and ideal family size for 26 European countries (13 for IFS), by completed family size for cohorts born around 1970.

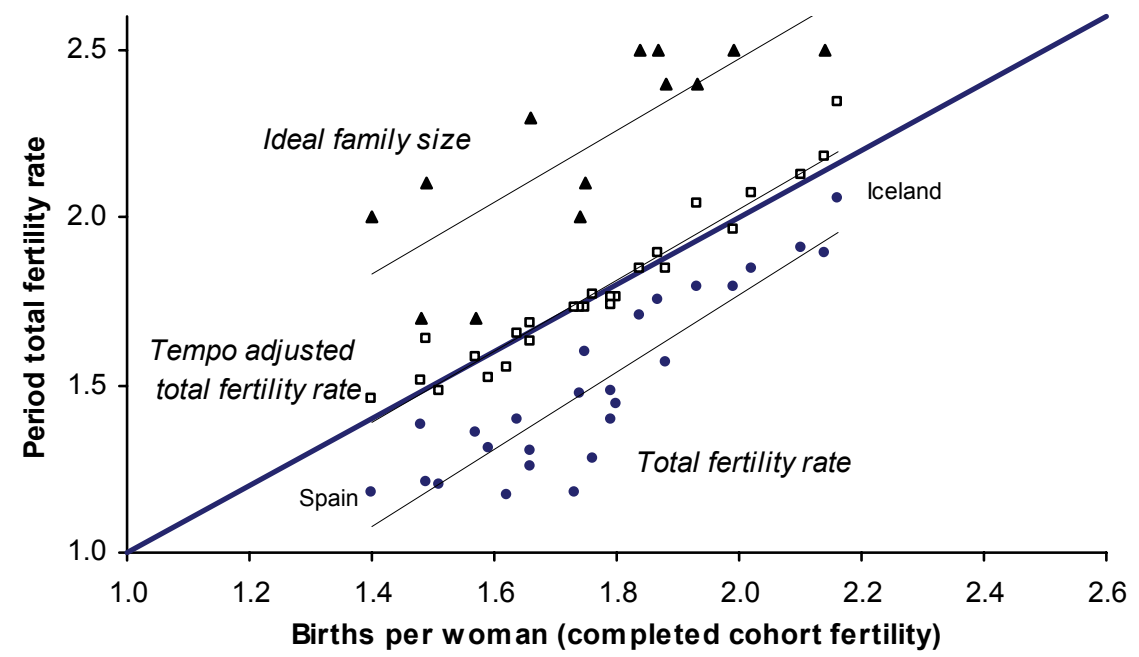

Sources: Sobotka 2004, Goldstein et al. 2003, Council of Europe 2006.

2 The cohorts born around 1970 have not reached the end of their childbearing years by 2006 . To estimate the completed fertility of these cohorts, Council of Europe (2006) assumes cohorts' age-specific fertility for the unobserved remaining years of childbearing to equal the agespecific rates observed in the last available year. 


\section{Why fertility indicators differ}

The finding that ideal family size exceeds current fertility as measured by the TFR is attributable to two general causes:

1) Obstacles to achieving ideal family size. Three types of obstacles exist:

- Economic: the high cost of children, including the direct costs associated with the bearing and rearing of children and the opportunity costs of childbearing for working parents. Opportunity costs have increased over time with rising levels of women's education and labour force participation. In addition, unemployment among young adults creates economic uncertainty and delays childbearing.

- Social: rising individualism, culturally defined gender roles, difficulty of finding a suitable partner, marital disruption (due to divorce or death of a spouse), differences between partner preferences, and a desire for a lifestyle or career that is incompatible with childbearing.

- Biological: the inability to conceive or carry a pregnancy to term. The risk of infertility rises with age and has become more prevalent in recent decades as childbearing has been postponed. Increasing numbers of women are "running out of time".

2) Tempo effects. As noted, the TFR is depressed whenever childbearing is being postponed. Figure 2 presents trends in the mean age at first birth for European countries, confirming that the age at first birth has risen over time in most countries. The tempo distortion of the TFR is directly proportional to the rates at

Figure 2:

Period mean age of mothers at first birth, 29 European countries, 1970-2006

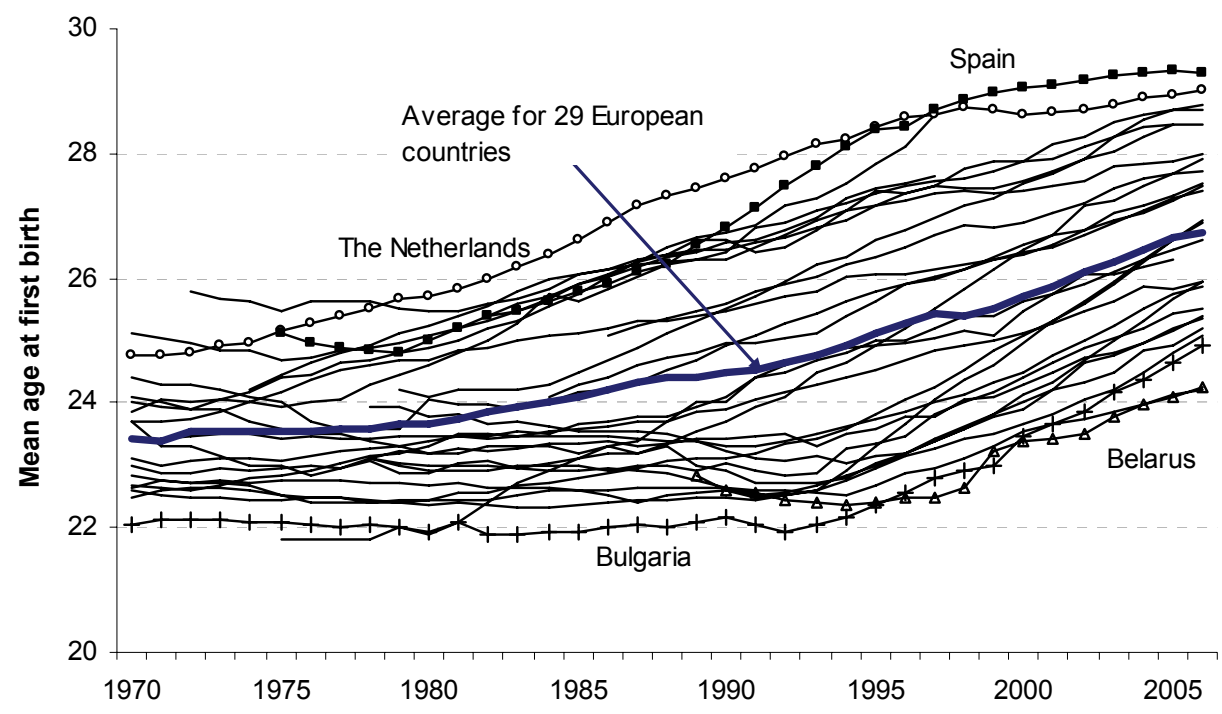

Sources: Council of Europe 2006, national statistical offices, and computations based on Eurostat 2008. 
which the mean ages at births of different orders are rising: an increase of 0.1 year per year in the mean age results in a $10 \%$ reduction in fertility and in a TFR that is $10 \%$ lower than the ATFR (assuming the shape of the age pattern of fertility at each birth order to remain invariant over time). This reduction lasts as long as the mean age rises, but disappears instantly whenever the postponement in childbearing ends. Without the ongoing postponement of childbearing the TFR would be at the level estimated by the adjusted TFR. In most European countries the mean age at childbearing has risen for more than two decades and it is not clear when this trend along with its fertility-reducing effect will end.

In addition to the obstacles and the tempo effect which depress the TFR relative to IFS, there are three other minor factors that have the opposite effect on the TFR: they raise fertility relative to ideal family size (Bongaarts 2001; Morgan 2003):

- Unwanted fertility: Although contraception is widely practiced and abortion is generally available, some unwanted births occur as the result of either non-use or the use and failure of contraception and an unwillingness or inability to undergo an abortion. Estimates of unwanted fertility are not readily available for developed countries, except in the United States. A 2002 US survey found that 14 per cent of births in the five years before the survey were unwanted at the time of conception and a further 21 per cent were mistimed (Chandra et al. 2005). Comparable estimates are not available for European countries, but the figures seem to be generally lower than in the US (Brown and Eisenberg 1995; Régnier-Loilier and Leridon, 2007; Testa and Toulemon 2006).

- Replacement of deceased children. The replacement of a child that has died increases the number of births a couple has without changing the desired family size, which is therefore one of the reasons why the former might exceed the latter. Replacement can only have a small impact on fertility in developed societies because less than one per cent of children die as infants. In such cases even complete replacement would raise fertility by only about 0.02 births per woman, which is small enough not to be of practical significance at the population level.

- Gender preferences: When stating a desired family size, respondents may have a specific gender composition in mind (e.g. one son and one daughter). In such cases parents may continue to have births after they have reached their desired number of children if their preferred gender composition has not been achieved. The existence of gender preferences can therefore lead to higher fertility than would be the case in their absence. While strong preferences for sons exist in a number of developing countries, gender preferences are generally weak in Europe. 


\section{Estimates of the obstacle and tempo effects}

Precise estimates of the separate roles of social, economic and biological obstacles are not possible due to a lack of detailed data. However, their approximate combined size can be deduced as follows. In a hypothetical population in which the three minor fertility-enhancing effects are absent, the total obstacle effect simply equals the difference between the IFS and the ATFR, because the removal of both the tempo effect and the obstacles would raise the TFR to the IFS. The difference between IFS and the ATFR averages 0.44 births per woman for the 13 countries for which estimates are available (this calculation assumes the IFS to be age-invariant and unaffected by the removal of various obstacles; this issue will not be pursued here for lack of data). Unfortunately, the fertility-enhancing factors are generally not negligible and the combined impact of the obstacles is therefore somewhat larger than suggested by this simple calculation. How much larger is unclear because there are hardly any estimates about the roles of unwanted fertility, gender preferences and replacement of deceased children but their joint impact is probably only a small fraction of one birth per woman in Europe, say on average around 0.1 or 0.2 births per woman. The total obstacle effect equals IFS minus ATFR plus this small enhancing factor. For the 13 European countries the average obstacle effect therefore equals around 0.59 births per woman (i.e. $0.44+0.15$ ).

Tempo effects can be estimated directly as the difference between observed and tempo-adjusted TFR. In the late 1990s the tempo distortion (ATFR-TFR) averaged 0.28 births per woman for the set of 26 countries listed in Table 1 (the average is 0.23 for subset of 13 countries).

The sum of the tempo and obstacle effects is of interest to policy makers because, as illustrated below, these effects are potentially subject to policies that reduce their size and hence raise fertility. For the 13 countries for which estimates of all three indicators are available this sum equals $0.23+0.59$ for a total of about 0.82 births per woman on average. If the average tempo effect of 0.28 births per woman for the 26 countries is used in this calculation the sum equals $0.28+0.59=$ 0.87 births per woman.

These averages provide a general magnitude of the factors causing differences between actual and preferred fertility in Europe in the late 1990s, but they hide substantial differences among countries. For example, the gap between the IFS and ATFR is less than 0.2 births per woman in Austria and West Germany, while it exceeds 0.6 in England and Wales, Finland and Greece. Country estimates of tempo effects range from less than 0.2 in France, West Germany, the Netherlands, England and Wales and Finland, to more than 0.4 births per woman in Italy, Estonia and Slovenia (see Table 1). These effect estimates for individual countries should be considered approximate because they contain measurement errors. Nevertheless, there are undoubtedly substantial differences among countries with 
respect to the sizes of both obstacle and tempo effects. This in turn implies differences in the potential impact of any pronatalist policies.

\section{Policy options and their potential fertility impact}

Pronatalist policies are most likely to succeed if they focus on closing the gap between ideal and actual period fertility. This goal can be achieved in two general ways:

1) Reduce obstacles

In theory, policies could be designed to address all three types of obstacleseconomic, social and biological. However, most of the actual proposals that have been implemented or are under discussion focus on measures to reduce economic costs only. A wide range of options exists on this topic (McDonald 2002) and only a general comment will be made here.

Economic incentives alone are likely to have only a modest impact on fertility for two reasons. First, the economic costs of childbearing and childrearing are large. For example, Longman (2004) estimates that the investment of US parents amounts to more than $\$ 1$ million per child. Government contributions or tax breaks of a few thousand dollars a year or less can therefore have only a marginal effect on the decision to have a child. Second, the total effect of all obstacles on the TFR is typically only around 0.6 births per woman. It is not possible to measure the separate contributions of economic, social and biological factors to this difference, but it is reasonable to assume that all three have some effect. The economic component alone might on average account for perhaps 0.2 or 0.3 births per woman. Of course, no actual policy can eliminate economic obstacles altogether so the actual effect is likely to be even smaller. Nevertheless, a wellfocused investment may have some impact. Indeed, countries in northern and western Europe with generous family support measures such as subsidised child care, reduced taxes for families with children and paid parental leaves have somewhat higher fertility than elsewhere in Europe. These observations about the potential impact of interventions are consistent with the conclusions of previous assessments which generally find modest effects for them (Caldwell et al. 2002; Calot 2006; Gauthier 2007; McDonald 2006)

Much less attention has been paid to social obstacles. This is understandable as governments are reluctant to interfere with the individual decision making underlying these obstacles. An exception is the attempt made by governments in Japan and Singapore to raise marriage rates among single women, since substantial proportions of women never marry and childbearing is largely confined to marriage in these societies. However, these efforts have apparently not yet been successful (McDonald 2006).

Biological obstacles are real and growing due to the rising mean age at childbearing. Modern medicine and biotechnology have developed an array of 
interventions to assist women and couples who have difficulties in conceiving or carrying a pregnancy to term. This technology is expensive but increasingly effective. With a wider application of existing technology, involuntary primary and secondary infertility could be reduced further, thus raising the TFR by a small but significant amount. Toulemon (1996) estimates that 7 per cent of French women born between 1930 and 1950 were unable to have a child but that medical intervention addressed this problem for 2 per cent of couples. In recent decades the proportion of couples with infertility problems has risen further with women postponing childbearing, but the ability of medical intervention to reverse this obstacle has also improved. For example, Sobotka et al. (2008) estimate that up to 7 per cent of children of native Danish women born in 1975 and later will likely be conceived by assisted reproductive technologies (ART). Further support for couples who have difficulties in reproducing and additional investment in biotechnology seem advisable and should be part of a comprehensive pronatalist policy.

\section{2) Reducing or eliminating tempo effects.}

As noted by Lutz and Skirbekk (2005), "population policies aimed at affecting the tempo of fertility are a new concept, and possibly a powerful and socially acceptable way to increase period fertility rates where these rates are considered to be too low" (p.715). Tempo policies are attractive because no major changes in behaviour are needed. Simply stopping the ongoing rise in the age at childbearing should result in an immediate rise of the TFR to the level of the ATFR as the tempo effect would disappear. For the 26 European countries listed in Table 1 such a rise would average at 0.28 births per woman. This rise in fertility will be larger in countries with the most rapid rises in the ages at childbearing and hence the largest tempo effects. An even larger impact on the TFR could be achieved by reversing the long-term rise in the mean age at childbearing. For example, if a country could manage to turn around an upward trend of 0.1 years per year in the mean age at childbearing and initiate a slow decline of just 0.1 year per year, the period TFR would increase by 20 per cent (from 10 per cent below to 10 per cent above the ATFR). This effect will last as long as the mean age keeps declining. Furthermore, a reduction in the mean age at childbearing would have an indirect effect of raising the quantum of fertility because at younger ages the biological obstacle becomes smaller. According to Kohler et al. (2002) every year of decline in the timing of childbearing could raise completed fertility by a few per cent.

The idea of tempo policies is relatively new and there has been little experience with them. Policies in Sweden and Austria favour a birth within 2 years after a previous birth (Andersson 1999; Hoem et al. 2001). Lutz and Skirbekk (2005) propose reforms in the school system to lower the age at completion of education, thus potentially affecting the timing of childbearing. Reducing unemployment among the young could also contribute to ending the 
trend towards postponement of childbearing. These and other ideas should be pursued more vigorously.

\section{Potential demographic impact of pronatalist policies}

The preceding analysis focused on options for raising fertility in low-fertility countries. However, higher fertility is not an end in itself, but rather a means to producing desirable demographic change. The dominant concern is population ageing that will occur if fertility remains at the current low levels. The question therefore is whether a small increase in fertility (of a few tenths of a birth per woman) that might be achieved by pronatalist policies does have a worthwhile impact on population ageing.

To shed light on this issue, a set of three projections to 2050 of the old-age dependency ratio (population 15-64/population 65+) will be compared. These three projections, prepared by the United Nations (2007b), make identical assumptions about migration and mortality but differ in their assumptions about future fertility trends for Europe as a whole. The projections are as follows:

1) Constant variant, leaves fertility at current low levels of 1.45 births per woman until 2050. This is slightly below the average of the 26 EU Member States in Table 1 because the UN includes all European countries in this aggregate projection.

2) Medium variant, assumes a modest increase in fertility, reaching a TFR of 1.76 births per woman in 2050. This scenario roughly expresses what would happen if tempo effects were to disappear over the next few decades.

3) High variant, fertility 0.5 births per woman above the medium variant from 2015 onwards. This scenario would raise the TFR to 2.26 in 2050 which is approximately the average IFS in Table 1 . While vigorous implementation of pronatalist and tempo policies might close the gap between IFS and TFR, it seems unlikely that this gap will disappear entirely which is why this projection must be considered very difficult to achieve.

Average TFRs for the entire projection period 2005-2050 equal 1.45, 1.61 and 2.07 births per woman, respectively, for the three variants. On average, the medium variant therefore exceeds the constant variant by 0.16 births per woman and the high variant exceeds the medium variant by 0.46 births per woman.

Figure 3 plots trends in the old-age dependency ratios for each of these projection variants. They are identical until 2020 because only after this date can a fertility decline initiated in 2005-2010 affect the population aged 15-64, and consequently the old-age dependency rate. As time progresses the impact of fertility changes on the old-age dependency ratio increases. By 2050 the old-age dependency ratio will rise by $114 \%$ (from 0.23 in 2005 to 0.50 in 2050) in the constant projection. This growth is slightly smaller $(105 \%)$ in the medium variant and substantially smaller (77\%) in the high variant. Clearly, the dependency ratio 
still rises over time even in the high variant, but there is a significant improvement over the constant variant.

\section{Figure 3:}

Projected old-age dependency ratio for Europe, 2010-2050

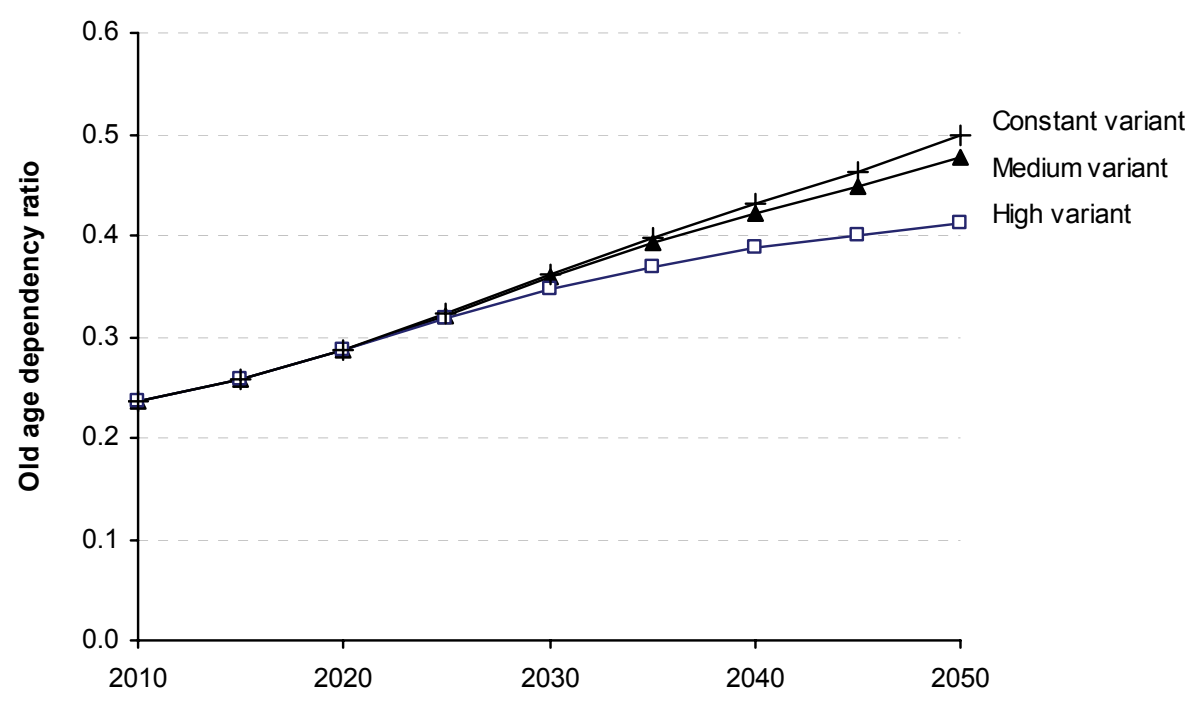

Source: United Nations 2007

Whether this reduction in the old-age dependency ratio is worth the investments required to implement pronatalist policies depends on the cost of alternative policies to address the growing burden of support and health care for ageing populations. This issue is beyond the scope of this paper.

Figure 4 plots these projections of the old-age dependency rate in 2050 by region within Europe. The amount of ageing expected in the constant fertility projection between 2005 and 2050 varies considerably, mostly due to regional differences in fertility. The largest increases are projected for eastern and southern Europe $(+135 \%)$ which are the regions with the lowest current fertility. In contrast the old-age dependency ratio is expected to grow by a more modest $78 \%$ in northern Europe and by $90 \%$ in western Europe where fertility is relatively high. The medium and high variant projections show the expected smaller increase in old-age dependency rates. 
Figure 4:

Old age dependency ratio in $\mathbf{2 0 0 5}$ and alternative projections for 2050

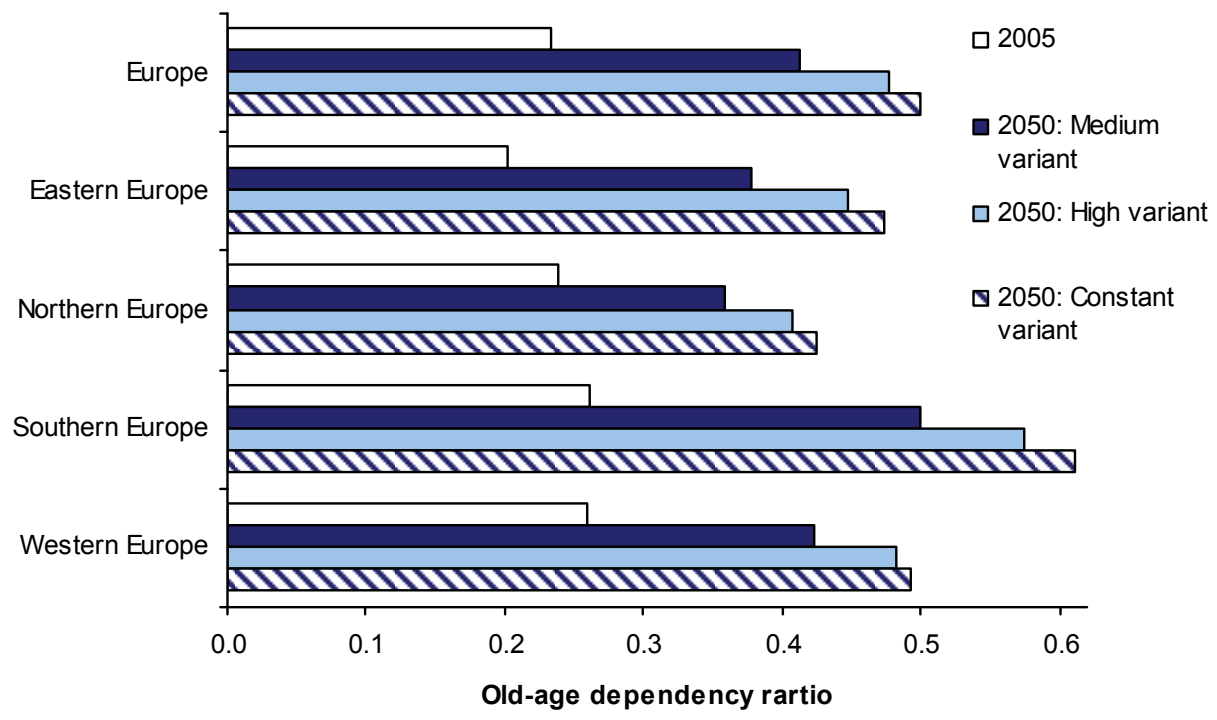

Source: United Nations 2007

\section{Conclusion}

Growing concerns about the adverse implications of population ageing are stimulating interest in efforts to directly or indirectly encourage higher fertility. The preceding analysis of levels and differences in fertility indicators provides support for different types of pronatalist policies. In particular, the finding that ideal family size exceeds actual fertility greatly facilitates policy formulation. Effective efforts to close this gap should be welcomed by individuals who will be assisted in achieving their ideal family size and they should benefit society by increasing period fertility and thus reducing population ageing.

The causes of this gap include economic, social and biological obstacles as well as tempo effects. The size of these factors varies substantially among countries but typical values are about 0.6 births per woman for the combined effect of the obstacles and about a quarter of one birth per woman for the tempo effect, resulting in a total average gap of around 0.8 to 0.9 births per woman. A comprehensive pronatalist policy should focus on all factors that cause actual fertility to be lower than the ideal level, not just economic ones. This means going beyond conventional economic measures that reduce the costs of childbearing and considering efforts to reduce biological and perhaps even social obstacles to childbearing. In addition, policies aimed at reducing or reversing the tempo distortion can have a substantial impact without requiring significant changes in behaviour. 
It appears that with a comprehensive policy and a substantial commitment of resources, fertility can be raised by a few tenths of a birth per woman above the level that would prevail without these policies. Effective tempo policies could result in even larger effects in the short run. Such effects would bring about a substantial reduction in the rise of the old-age dependency ratio by 2050 , but would fall well short of halting population ageing. Nevertheless, the challenges posed by population ageing are so critical and so difficult to address that any step in the right direction is beneficial.

\section{References}

Andersson, G. 1999. "Childbearing trends in Sweden 1961-1997." European Journal of Population 15(1): 1-24.

Andersson, G. and G. Neyer (eds.) 2004. Contemporary Research on European Fertility: Perspectives and Developments. Special Collection 3. Demographic Research, 17 April 2004. «http://www.demographic-research.org/special/3/».

Bongaarts, J. and G. Feeney. 1998. "On the quantum and tempo of fertility." Population and Development Review 24(2): 271-291.

Bongaarts, J. and G. Feeney. 2006. "The quantum and tempo of life cycle events". Vienna Yearbook of Population Research 2006: 115-151.

Bongaarts, J. 2001. "Fertility and reproductive preferences in post-transitional societies." In: J. Casterline and R. Bulatao (eds.) Global fertility transition. Supplement to Population and Development Review 27: 260-281.

Brown, S. and L. Eisenberg. 1995. The best intentions: unintended pregnancy and the wellbeing of children and families. Committee on Unintended Pregnancy, Institute of Medicine. Washington DC, National Academy of Sciences.

Caldwell, J., P. Caldwell, and P. McDonald. 2002. "Policy responses to low fertility and its consequences: A global survey." Journal of Population Research 19(1): 1-24.

Caldwell, J. and T. Schindlmayr. 2003. "Explanations of the fertility crisis in modern societies: A search for commonalities." Population Studies 57(3): 241-263

Calot, G. 2006. "The impact of pronatalist policies." In: G. Caselli, et al. (eds.) Demography: analysis and synthesis. London, Academic Press, pp. 505-554.

Chand, S. and A. Jaeger. 1996. "Aging populations and public pension schemes." IMF Occasional Paper Number 147. Washington, DC, International Monetary Fund.

Chandra A., G. M. Martinez, W. D. Mosher, J.C. Abma, and J. Jones. 2005. "Fertility, family planning, and reproductive health of U.S. women: Data from the 2002 National Survey of Family Growth." Vital and Health Statistics, Series 23 (No. 25), National Center for Health Statistics: pp.1-174. «http://www.cdc.gov/nchs/data/series/sr_23/sr23_025.pdf».

Commission of the European Communities. 2006. "The demographic future of Europe from challenge to opportunity." $\operatorname{COM}(2006)$ 571, Brussels, 12.10.2006 «http://ec.europa.eu/employment_social/news/2006/oct/demography_en.pdf».

Council of Europe. 2006. Recent Demographic Developments in Europe 2005. Strasbourg, Council of Europe Publishing. 
Demeny, P. 2003. "Population Policy.” In: International Encyclopedia of Population. P. Demeny and G. McNicoll (eds.) New York, MacMillan Reference, pp. 752-763.

Eurostat. 2008. Population and Social Conditions. Online database accessed in May 2008 at «http://epp.eurostat.ec.europa.eu».

Frejka, T., T. Sobotka, J. M. Hoem, and L. Toulemon (eds.) 2008. Childbearing Trends and Policies in Europe. Demographic Research, Special Collection 7, Vol. 19, Articles 1-29, pp. 1-1178. «http://www.demographic-research.org/special/7/».

Hoem, J., A. Prskawetz, G. Neyer. 2001. "Autonomy or conservative adjustment? The effect of public policies and educational attainment on third births in Austria, 1975-96." Population Studies 55(3): 249-261.

Gauthier, A. 2007. "The impact of family policies on fertility in industrialized countries: a review of the literature." Population Research and Policy Review 26(3): 323-346

Goldstein, J., W. Lutz, and M. R. Testa. 2003. "The emergence of sub-replacement family size ideals in Europe." Population Research and Policy Review 22: 479-496.

Kohler, H.-P. and J. A. Ortega. 2002. "Tempo-Adjusted Period Parity Progression Measures, Fertility Postponement and Completed Cohort Fertility." Demographic Research 6(6): pp. 91-144.

Kohler, H.-P., F. C. Billari, and J. A: Ortega. 2002. "The emergence of lowest-low fertility in Europe during the 1990s." Population and Development Review 28(4): 641-680.

Kohler, H.-P., F. C. Billari, and J. A. Ortega. 2006. "Low fertility in Europe: Causes, implications and policy options." In F. R. Harris (ed.) The Baby Bust: Who will do the Work? Who Will Pay the Taxes? Lanham, MD: Rowman \& Littlefield Publishers, pp. 48-109.

Longman, P. 2004. The Empty Cradle: How Falling Birthrates Threaten World Prosperity and What to Do About It. New York, Basic Books.

Lutz, W. and V. Skirbekk. 2005. "Policies Addressing the Tempo Effect in Low-Fertility Countries." Population and Development Review 31(4): 699-720.

McDonald, P. 2000. "Gender equity in theories of fertility transition." Population and Development Review 26(3): 427-439.

McDonald, P. 2002. "Sustaining fertility through public policy: The range of options." Population-E 57(3): 417-446.

McDonald, P. 2006. "Low fertility and the state: The efficacy of policy." Population and Development Review 32(3): 485-510.

Morgan, S. P. and M. G. Taylor. 2006. "Low fertility at the turn of the twenty-first century." Annual Review of Sociology 32: 375-399.

Morgan, S. P. 2003. "Is low fertility a 21 st Century demographic crisis?". Demography 40(4): 589-603.

OECD. 1998. Maintaining Prosperity in an Ageing Society. Paris, OECD Publications.

OECD. 2001. "The fiscal implications of ageing: Projections of age-related spending." OECD Economic Outlook, June 2001.

OECD. 2006. Live Longer Work Longer. Paris, OECD Publications.

Régnier-Loilier, A. and H. Leridon, 2007. "After forty years of contraceptive freedom, why so many unplanned pregnancies in France?" Population \& Societies 439: 1-4. «http://www.ined.fr/fichier/t_publication/1336/publi_pdf2_pesa439.pdf».

Sobotka, T. 2003. "Tempo-quantum and period-cohort interplay in fertility changes in Europe. Evidence from the Czech Republic, Italy, the Netherlands and Sweden.” Demographic Research 8(6): 151-214. 
Sobotka, T.. 2004. "Is lowest-low fertility in Europe explained by the postponement of childbearing?" Population and Development Review 30(2): 195-220.

Sobotka, T. 2008. "Does persistent low fertility threaten the future of European populations?" In: J. Surkyn, P. Deboosere and J. Van Bavel (eds.) Demographic Challenges for the 21st Century. Brussels, VUB.

Sobotka, T., M. A. Hansen, T. K. Jensen, A. T. Pedersen, W. Lutz, and N. E. Skakkebæk. 2008. "The contribution of assisted reproduction to completed fertility: An analysis of Danish data." Population and Development Review 34(1): 79-101.

Testa, M. R. and L. Toulemon. 2006. "Family Formation in France: Individual Preferences and Subsequent Outcomes." Vienna Yearbook of Population Research 2006: 41-75.

Toulemon, L. 1996. "Few couples remain voluntarily childless." Population: An English Selection 8: 1-28.

United Nations. 2007a. World Economic and Social Survey 2007: Development in an Ageing World. Department of Economic and Social Affairs, United Nations: New York.

United Nations. 2007b. World Population Prospects: The 2006 Revision. United Nations Population Division, New York.

Van de Kaa, D. 2006. "Temporarily New: On Low Fertility and the Prospect of Pro-natal Policies." Vienna Yearbook of Population Research 2006: 193-211.

World Bank. 1994. Averting the Old-age Crisis: Policies to Protect the Old and Promote Growth. World Bank Policy Research Report. Oxford: Oxford University Press. 